\title{
MICROPROPAGATION OF Ziziphus jujuba Mill. (JUJUBE) THROUGH SHOOT TIP AND NODAL SEGMENT CULTURE
}

\author{
KP Hansika ${ }^{1}$, AL Ranawake $^{1 *}$ and RNI Perera ${ }^{2}$ \\ ${ }^{1}$ Department of Agricultural Biology, Faculty of Agriculture, University of Ruhuna, Mapalana, Kam- \\ burupitiya, Sri Lanka \\ ${ }^{2}$ Division of Biotechnology, Fruit Research and Development Institute, Horana, Sri Lanka
}

\begin{abstract}
Jujube is known as Masan in Sri Lanka is one of the underutilized fruit crops. It is important due to its high nutritious value and introduced as a potential crop for commercial cultivation. Micropropagation using plant tissue culture is an efficient method for vegetative propagation of commercially important crops for mass production to meet the demands of planting materials. Present study was carried out to develop a proper in-vitro protocol for local varieties of Jujube to produce planting materials. The most suitable fungicide for surface sterilization procedure was selected by testing Captan (Captan 50\%, 1.2 g/l), Topsin (Thiophanate methyl 70\%, 2 g/l), and Daconil (Chlorothalonil, $1.8 \mathrm{ml} / \mathrm{l})$. Selection of a suitable concentration of BAP (Benzyle Amino Purine) or TDZ (Thidiazuron) for shoot proliferation was assessed in four different concentrations of BAP (1, 1.5, 2, 2.5 mg/l) and of TDZ (0.1, 0.2, 0.3, 0.4 mg/l) and IBA (Indole Butric Acid) for root induction in two concentrations of IBA (1, 2 $\mathrm{mg} / \mathrm{l})$. Dipping shoot tips in Captan solution for 20 minutes gave the highest significant non-contamination percentage $(79.9 \%)$ and lowest fungal radius $(0.15 \mathrm{~cm})$ of contaminated cultures among three treatments. MS (Murrashige and Skoog) medium containing $1.5 \mathrm{mg} / \mathrm{l}$ BAP recorded significantly highest percentage of elongated bud $(96.66 \%)$ and newly produced shoot length $(1.08 \mathrm{~cm})$ and lowest significant rate was recorded in TDZ 0.2 $\mathrm{mg} / \mathrm{l}(3.33 \%)$. Callus was produced in all the concentrations of TDZ. None of the concentrations of BAP or TDZ produced multiple shoots. Elongated nodal segments in BAP (1, 1.5 mg/l) could be successfully sub-cultured for further multiplication. Rooting was not recorded in both shoot tips and in-vitro generated shoots during four weeks of culturing on IBA contained media.
\end{abstract}

Key words: Ziziphus jujuba Mill., in-vitro propagation, shoot tips, direct shoot induction

\section{INTRODUCTION}

Jujube (Ziziphus jujuba Mill.) commonly known as Masan in Sri Lanka is a perennial fruit tree belongs to genus Ziziphus of family Rhamnaceae. Fruits of Jujube are becoming important due to its high nutritious value. Jujube contains good amount of vitamin $\mathrm{C}$ and $\mathrm{B}$ complexes (Pareek, 2002), minerals (San et al., 2009), high amount of antioxidant content (Johnstone, 2012) and excellent source of ascorbic acid and carotenoids (Abbas, 1997). Due to the economic importance, Jujube is commercially cultivated in several countries including China, India, Korea, Japan and Mediterranean countries (Azam-Ali, 2006).

*Corresponding author: lankaranawake@hotmail.com
Jujube is categorized as underutilized fruit crop in Sri Lanka and introduced as a potential crop for commercial cultivation by the Department of Agriculture (Ketipeaarachchi, 2015). In order to promote the cultivation, various propagation methods have been investigated. Jujube can be propagated through seeds and by vegetative methods. Seed propagation is not generally use for fruit production due to its heterozygous nature (Azam-Ali, 2006). Although it is possible to multiply through budding and grafting techniques, the rate of multiplication is very low. Thus to meet the demand of the planting materials for commercialization, it is necessary to obtain a true to type plants through a method of rapid propa- 
gation. Micropropagation using plant tissue culture techniques is an efficient method of vegetative propagation of various perennial trees. The tissue culture of $Z$. jujuba Mill. was successfully obtained for several distinguished cultivars via leaf (Li et al., 2002; Gu et al., 2005; Chen et al., 2008; Feng et al., 2010; Ma et al., 2012; Ye et al., 2012), embryos (Liu and Qi, 2003, Kim et al., 2006), cotyledons (Kim et al., 2006) and nodal ex-plants (Goyal et al., 2006; Soliman and Hegazi, 2013). However, the response of the planting material on tissue culture media depends on the genotype and therefore, it is important to develop a proper in-vitro protocol for Jujube varieties adapted to Sri Lankan condition to promote the commercial scale cultivation. Therefore the present study was carried out with the objectives of determining the most suitable fungicide treatment in surface sterilization procedure, to determine a suitable concentration of BAP or TDZ for shoot induction and to determine a suitable concentration of IBA for root induction of local varieties of Jujube.

\section{MATERIALS AND METHOD}

The study was carried out in the Plant Tissue Culture Laboratory at Fruit Research and Development Institute Horana, Sri Lanka during July 2016 to December 2016.

\section{Planting materials}

Nodal segments $(1.5 \mathrm{~cm}$ length) of Jujube were obtained from a healthy, fruit yielding mature trees growing in the conservation garden of Fruit Research and Development Institute, Horana, Sri Lanka.

\section{Surface sterilization}

Collected ex-plants were washed under running tap water with few drops of Teepol for one hour. Then they were dipped in three fungicide solutions Captan (1.2 g/l), Topsin (2 g/l) and Daconil $(1.8 \mathrm{ml} / \mathrm{l})$ for 20 minutes in each solution separately. Then the ex-plants were washed out with doubled distilled water and shook in 20\% Chlorex solution for 15 minutes followed by three rinses of doubled distilled water at the laminar air flow cabinet.

\section{Culture medium and conditions}

Ex-plants were cultured on MS basal medium (Murashige and Skoog, 1962) gelled with 7.8 $\mathrm{g} / \mathrm{l}$ Bacteriological agar. The $\mathrm{pH}$ of the medium was adjusted to 5.8 using $0.1 \mathrm{M} \mathrm{NaOH}$ prior to autoclaving at a pressure of $1.05 \mathrm{kgcm}^{-2}$ and $121^{\circ} \mathrm{C}$ for 20 minutes. All cultures were incubated in a culture room at $26 \pm 2{ }^{\circ} \mathrm{C}$ with 3000 lux light intensity provided by cool white fluorescent lamps for $16 \mathrm{hr}$ photoperiod.

\section{Selection of most suitable fungicide treat- ment}

Surface sterilized nodal segments were trimmed into one $\mathrm{cm}$ segments and they were cultured vertically on MS basal medium separately according to three fungicide treatments for three weeks to determine the most suitable fungicide treatment in surface sterilization protocol. Fungal radius of the contaminated cultures was measured at four day interval for 20 days.

\section{Culture establishment}

The fungicide treatment which gave the highest non-contaminated cultures was selected as the surface sterilization for the shoot tips and nodal segments before culturing them on MS basal medium fortified with four different concentrations of $\operatorname{BAP}(1,1.5,2,2.5 \mathrm{mg} / \mathrm{l})$ and TDZ $(0.1,0.2,0.3,0.4 \mathrm{mg} / \mathrm{l})$ and incubated for four weeks. The percentages of ex-plants initiated growth, percentages of ex-plants produced new shoots, average number of shoots per ex-plant and shoot length $(\mathrm{cm})$ were measured after four weeks of culture.

\section{Shoot multiplication}

In-vitro nodal segments obtained from cultures of MS basal medium fortified with BAP at 1 and $1.5 \mathrm{mg} / 1$ concentration were sub cultured on same medium for further multiplication. The percentages of ex-plants produced new shoots, average number of shoots per ex-plant and shoot length $(\mathrm{cm})$ were measured after four weeks of culture. 


\section{Root induction}

Nodal segments and in-vitro shoots were cultured on MS basal medium supplemented with IBA at 1 and $2 \mathrm{mg} / 1$ concentrations and incubated for four weeks. Root initiation was observed.

\section{Statistical Design and Analysis of Data}

Analysis of variance (ANOVA) and Duncan's multiple range test for mean separation were performed to analyze the data using statistical analysis software; SAS institute inc., (2000). Ten cultures were raised for each treatment with three ex-plants per each culture vessel. Experiment was carried out according to Randomized Complete Block Design to test the effectiveness of three fungicide treatments and shoot induction, shoot multiplication and root induction experiments were carried out according to Completely Randomized Design. The differences among averages of the recorded parameters for all treatments were tested for significance at 5\% level.

\section{RESULTS AND DISCUSSION}

Effectiveness of fungicide treatment in surface sterilization of ex-plant

Dipping ex-plants in Captan (Captan 50\%) fungicide solution for 20 minutes which produced $79.9 \%$ cultures free of contamination after 20 days of culturing was the most effective fungicide treatment for surface sterilization of nodal segments (Table 4.1).

Table 4.1: Non-contamination percentages of cultures in three different fungicide treatments Topsin, Daconil and Captan used for surface sterilization

\begin{tabular}{cccc}
\hline $\begin{array}{c}\text { Evaluated day } \\
\text { after culturing }\end{array}$ & Topsin & Daconil & Captan \\
\hline $4^{\text {th }}$ day & $96.6^{\mathrm{a}}$ & $76.4^{\mathrm{b}}$ & $100^{\mathrm{a}}$ \\
$8^{\text {th }}$ day & $83.2^{\mathrm{a}}$ & $33.1^{\mathrm{b}}$ & $93.2^{\mathrm{a}}$ \\
$12^{\text {th }}$ day & $63.1^{\mathrm{a}}$ & $16.6^{\mathrm{b}}$ & $93.2^{\mathrm{a}}$ \\
$16^{\text {th }}$ day & $46.6^{\mathrm{b}}$ & $16.6^{\mathrm{b}}$ & $86.5^{\mathrm{a}}$ \\
$20^{\text {th }}$ day & $46.6^{\mathrm{b}}$ & $13.3^{\mathrm{b}}$ & $79.9^{\mathrm{a}}$ \\
\hline
\end{tabular}

The same letters within the same row are not significantly different at $\mathrm{P} \leq 0.05$
Lowest average fungal spreading of contaminated cultures with respect to fungal radius $(0.15 \mathrm{~cm})$ was also low in treatment using Captan after 20 days of culture (Table 4.2).

Table 4.2: Growth rate of fungus after contamination calculated as average fungal radius $(\mathrm{cm})$ in the tissue culture medium treated with Topsin, Daconil, Captan.

\begin{tabular}{llll}
\hline $\begin{array}{l}\text { Evaluated day } \\
\text { after culturing }\end{array}$ & Topsin & Daconil & Captan \\
\hline $4^{\text {th }}$ day & $0.0083^{\mathrm{b}}$ & $0.1583^{\mathrm{a}}$ & $0.0000^{\mathrm{b}}$ \\
$8^{\text {th }}$ day & $0.0917^{\mathrm{b}}$ & $0.5167^{\mathrm{a}}$ & $0.0330^{\mathrm{b}}$ \\
$12^{\text {th }}$ day & $0.2583^{\mathrm{b}}$ & $0.6250^{\mathrm{a}}$ & $0.0583^{\mathrm{b}}$ \\
$16^{\text {th }}$ day & $0.4580^{\mathrm{ab}}$ & $0.6583^{\mathrm{a}}$ & $0.0833^{\mathrm{b}}$ \\
$20^{\text {th }}$ day & $0.4083^{\mathrm{ab}}$ & $0.7083^{\mathrm{a}}$ & $0.1500^{\mathrm{b}}$ \\
\hline
\end{tabular}

The same letters within the same row are not significantly different at $\mathrm{P} \leq 0.05$

\section{Culture establishment}

MS basal medium supplemented with various cytokinins (BAP and TDZ) at different concentrations showed that shoot tips and nodal segments of studied cultivar of Jujube could initiate growth on all tested media. The use of MS medium is recommended according to Goyal et al. (2006) who reported that for the micropropagation of Ziziphus jujuba using nodal ex-plants, MS basal medium was found to be the best among different tested media (B5 and N6) compositions.

After two weeks of culture, bud initiation was observed in the shoot tips and nodal segment ex-plants in MS basal medium with or without any plant hormone (Figure $1 \mathrm{~A})$. Data obtained after two weeks of culture revealed that the percentage of ex-plants initiated bud was significantly affected by the type of hormone as it was not significantly different in control and BAP treatments and significantly different with TDZ treatments. Among the tested concentrations, MS basal medium supplemented with BAP at a concentration of $1 \mathrm{mg} / \mathrm{l}$ gave the highest percentage of initiated bud which is not significantly different compared to the other BAP concentrations and the control, for 
both shoot tips and nodal segment ex-plants (Table 4.3).

According to the data obtained after four weeks of culture, the percentage of elongated buds was significantly affected by the type of plant hormone and the concentration. Highest percentage of elongated buds $(96.66 \%)$ was obtained in the MS basal medium supplemented with BAP at a concentration of 1.5 $\mathrm{mg} / \mathrm{l}$ while lowest percentage $(3.33 \%)$ was recorded for the treatment using TDZ at a concentration of $0.2 \mathrm{mg} / 1$ (Table 4.3). There was a significant difference between the control and BAP treatments in shoot elongation (Figure 1B). Such effects due to known effects of cytokinin in promoting axillary shoot production and its role in plant morphogenesis (Hopkins and Muner, 2008).

No shoot proliferation was recorded in all the tested concentrations of both BAP and TDZ. There was no significant different in control and BAP treatments with respect to the length of shoots of number of ex-plants produced shoots. However it was significantly different in TDZ treatments where the lowest shoot lengths $(0.4$ and $0.5 \mathrm{~cm})$ were recorded in explants cultured on MS basal medium supplemented with TDZ at 0.1 and $0.2 \mathrm{mg} / 1$ concentrations respectively (Table 4.3). This may be due to the one of the undesirable side effect of TDZ is that cultures of some woody species including Ziziphus jujuba occasionally form stunted shoots (Lu, 1993).

Shoot tip and nodal segment ex-plants showed callusing in all treatments of TDZ at varying percentages. Initially callus developed at the cut end and latter on entire stem and leaf primodia were callused (Figure $1 \mathrm{C}$ ). Callus growth and proliferation was higher in media containing TDZ at $0.4 \mathrm{mg} / 1$ concentration (Table 4.4).

Table 4.4: Effect of TDZ concentration on shoot initiation of $Z$. jujuba

\begin{tabular}{ll}
\hline TDZ & \% ex-plants (callus \\
concentration & $\begin{array}{l}\text { induction) } \\
\text { ind }^{\mathrm{d}}\end{array}$ \\
\hline Control & $0.00^{\mathrm{d}}$ \\
$0.1 \mathrm{mg} / 1$ & $40.00^{\mathrm{c}}$ \\
$0.2 \mathrm{mg} / 1$ & $33.33^{\mathrm{c}}$ \\
$0.3 \mathrm{mg} / 1$ & $70.00^{\mathrm{b}}$ \\
$0.4 \mathrm{mg} / 1$ & $93.33^{\mathrm{a}}$ \\
\hline
\end{tabular}

The same letters within the same row are not significantly different at $\mathrm{P} \leq 0.05$

Similar results were obtained in the study of Sudhersan et al. (2000) on Ziziphus mauritia$n a \mathrm{cv}$. Umran. However in contrast to results obtained in the present study Soliman and Hegazi, (2013) reported shoot initiation from more than $80 \%$ of ex-plants Ziziphus jujuba

Table 4.3: Effect of MS basal medium and hormones on in-vitro establishment of nodal segments of Jujube

\begin{tabular}{|c|c|c|c|c|}
\hline $\begin{array}{l}\text { Hormone con- } \\
\text { centration mg/l }\end{array}$ & $\begin{array}{l}\% \text { of } \\
\text { ex-plants initiated } \\
\text { buds by } \\
\text { the } 14^{\text {th }} \text { day }\end{array}$ & $\begin{array}{l}\text { \% of } \\
\text { elongated buds } \\
\text { by } \\
28^{\text {th }} \text { day }\end{array}$ & $\begin{array}{l}\text { Average shoot } \\
\text { length of } \\
\text { newly produced } \\
\text { buds }(\mathrm{cm})\end{array}$ & $\begin{array}{l}\text { Average number } \\
\text { of shoots } \\
\text { per ex-plant }\end{array}$ \\
\hline Control & $90^{\mathrm{a}}$ & $23.33^{\mathrm{c}}$ & $0.95^{\mathrm{ab}}$ & $1.0^{\mathrm{a}}$ \\
\hline $1 \mathrm{mg} / \mathrm{l} \mathrm{BAP}$ & $100^{\mathrm{a}}$ & $93.33^{\mathrm{a}}$ & $0.99^{\mathrm{ab}}$ & $1.0^{\mathrm{a}}$ \\
\hline $1.5 \mathrm{mg} / 1 \mathrm{BAP}$ & $96.67^{\mathrm{a}}$ & $96.66^{\mathrm{a}}$ & $1.08^{\mathrm{a}}$ & $1.0^{\mathrm{a}}$ \\
\hline $2 \mathrm{mg} / \mathrm{l} \mathrm{BAP}$ & $93.33^{\mathrm{a}}$ & $43.32^{\mathrm{b}}$ & $0.87^{\mathrm{ab}}$ & $1.0^{\mathrm{a}}$ \\
\hline $2.5 \mathrm{mg} / 1 \mathrm{BAP}$ & $90.00^{\mathrm{a}}$ & $19.99^{\mathrm{cd}}$ & $0.8^{\mathrm{b}}$ & $1.0^{\mathrm{a}}$ \\
\hline $0.1 \mathrm{mg} / 1 \mathrm{TDZ}$ & $34.23^{\mathrm{b}}$ & $6.66^{\mathrm{de}}$ & $0.4^{\mathrm{c}}$ & $1.0^{\mathrm{a}}$ \\
\hline $0.2 \mathrm{mg} / 1 \mathrm{TDZ}$ & $33.26^{\mathrm{b}}$ & $3.33^{\mathrm{e}}$ & $0.5^{\mathrm{c}}$ & $1.0^{\mathrm{a}}$ \\
\hline $0.3 \mathrm{mg} / 1 \mathrm{TDZ}$ & $33.33^{\mathrm{b}}$ & $0.00^{\mathrm{e}}$ & 0.0 & 0.0 \\
\hline $0.4 \mathrm{mg} / 1 \mathrm{TDZ}$ & $33.33^{\mathrm{b}}$ & $0.00^{\mathrm{e}}$ & 0.0 & 0.0 \\
\hline
\end{tabular}

The same letters within the same row are not significantly different at $\mathrm{P} \leq 0.05$ 
Mill. in TDZ at higher concentrations $(0.5$ $\mathrm{mg} / \mathrm{l}, 1 \mathrm{mg} / \mathrm{l}$ and $2 \mathrm{mg} / \mathrm{l})$. Generally the composition of the basal medium, the category and the concentration of plant hormones are the key factors influencing adventitious shoot induction (Feng et al., 2010). According to the results of the present study BAP induced the shoot induction of Jujube at lower concentrations and the media containing TDZ suppressed the shoot growth and induced callusing. TDZ has been reported as most active cytokinin like substance to induce adventitious shoot formation in a number of species, especially woody plants ( $\mathrm{Lu}, 1993$ ) including Z. jujuba (Gu and Zhang, 2005). However, at concentrations higher than $1 \mu \mathrm{M}$, TDZ can stimulate the formation of callus, adventitious shoots or somatic embryos (Lu, 1993).

\section{Shoot multiplication}

The nodal segments of in-vitro plantlets when subcultured on the MS basal medium supplemented with BAP at $1 \mathrm{mg} / \mathrm{l}$ and $1.5 \mathrm{mg} / \mathrm{l}$ concentrations, produced shoot bud from each node. No elongation of nodal segments and shoot proliferation were observed (Figure 1 D). Survival percentage and growth percentage reached to $100 \%$ on tested treatments. These in-vitro nodal segments responded as fresh ex-plants on the medium when subcultured and produced shoots without dwarfing with respect to the length of the shoots (Table 4.5). No multiplication of shoots was ob-

Table 4.5: Effect of BAP concentration on shoot multiplication on in-vitro nodal segments of subculturing

\begin{tabular}{lll}
\hline $\begin{array}{l}\text { Cytokinin } \\
\text { concentration }\end{array}$ & $\begin{array}{l}\text { \% of shooted } \\
\text { ex-plants } \\
\text { after 28 days } \\
\text { of culture }\end{array}$ & $\begin{array}{l}\text { Average } \\
\text { shoot } \\
\text { length } \\
\text { (cm) }\end{array}$ \\
\hline Control & $13.33^{\mathrm{b}}$ & $0.87^{\mathrm{b}}$ \\
$1 \mathrm{mg} / 1 \mathrm{BAP}$ to $1 \mathrm{mg} /$ & $80.00^{\mathrm{a}}$ & $1.17^{\mathrm{a}}$ \\
& & $1.18^{\mathrm{a}}$ \\
\hline $1.5 \mathrm{mg} / \mathrm{l} \mathrm{BAP}$ to 1.5 & $93.33^{\mathrm{a}}$ & \\
\hline
\end{tabular}

The same letters within the same row are not significantly different at $\mathrm{P} \leq 0.05$ served within 30 days of culture.

Shoot multiplication of several distinguished cultivars of Ziziphus jujuba was successfully achieved with MS basal medium supplemented with BAP at 1 and $1.5 \mathrm{mg} / \mathrm{l}$ concentrations. Chinese Jujube Dongzao regenerated shoots were grown and proliferated on MS medium containing $1 \mathrm{mg} / \mathrm{l}$ BAP with multiplication coefficient of 3.2 (Wang et al., 2010). Multiplication of $Z$. jujuba cv. Comethry was achieved with BAP at $1,1.5$ and $2 \mathrm{mg} / \mathrm{l}$ concentrations with an average of 3.13 shoots per ex-plant (Soliman and Hegazi, 2013). Multiplication of the studied cultivar in this experiment may be achieved with BAP in long term with regular subculturing as in some cultivars of Jujube, higher rate of shoot multiplication was obtained in long term subculturing. One hundred and six shoots per single shoot tip obtained after six months of culture of $Z$. jujuba cv. Huizao (Abbas et al., 2014).

\section{Root Induction}

No rooting response was obtained for both shoots and in-vitro shoots when cultured on MS basal medium containing IBA at 1 and 2 $\mathrm{mg} / \mathrm{l}$ concentrations within the period of four weeks. These results were in agreement with the cultivar Zaytoni of Z. jujuba reported by Abbas et al., (2014) and with the results of cultivar Umran of $Z$. mauritiana reported by Sudhersan et al. (2000) where no adventitious root induction occurred at even higher concentrations of IBA on MS basal medium. However $79 \%$ of rooting rate was obtained on MS basal medium in cultivar Comethry of Z. jujuba Mill. at $2 \mathrm{mg} / \mathrm{l} \mathrm{IBA}$ concentration after eight weeks of culture (Soliman and Hegazi, 2013).

\section{CONCLUSION}

The most effective fungicide treatment was the Captan (Captan 50\%) at $1.2 \mathrm{~g} / 1$ concentration in the surface sterilization procedure of Jujube shoot tips and nodal segments out of other two tested fungicides Topsin (Thiophanate methyl 70\%) and Daconil 
(Chlorothalonil) with highest noncontamination percentage $(79.9 \%)$ and with lowest fungal spreading $(0.15 \mathrm{~cm})$. The best medium for in-vitro establishment of Jujube was MS basal medium supplemented with BAP at $1.5 \mathrm{mg} / \mathrm{l}$ concentration with respect to higher percentage of elongated bud $(96.66 \%)$ and higher shoot length $(1.08 \mathrm{~cm})$ of explants produced shoots. BAP or TDZ failed to produce multiple shoots of Jujube in the tested concentrations in MS basal medium. TDZ at concentrations of $0.1,0.2,0.3,0.4 \mathrm{mg} / \mathrm{l}$ can be used for the callus induction in plant regeneration program in future. Elongated shoots in BAP $(1,1.5 \mathrm{mg} / \mathrm{l})$ could be successfully subcultured in the same media for further shoot multiplication. Root induction of Jujube cannot be achieved in MS basal medium supplemented with IBA at 1 or $2 \mathrm{mg} / 1$ concentrations using shoot tips or in-vitro generated explants within four weeks period.

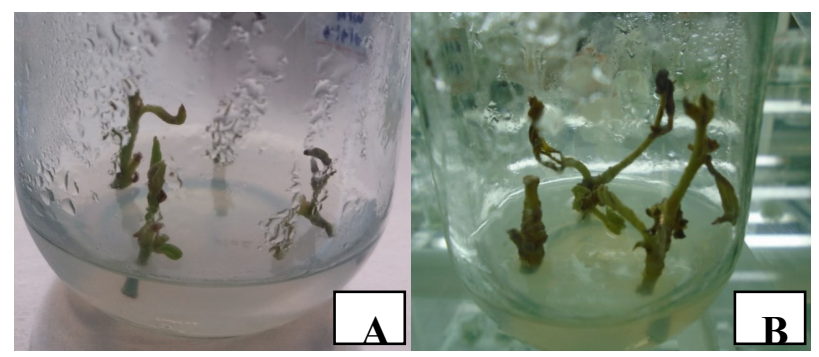

Figure 1: A- Growth initiation of shoot tips cultured on MS basal medium fortified with BAP $1.5 \mathrm{mg} / \mathrm{l}$ after two weeks of culture B- Growth and elongation of shoot tips in MS basal medium supplemented with BAP $1.5 \mathrm{mg} / \mathrm{l}$ after four weeks of culture

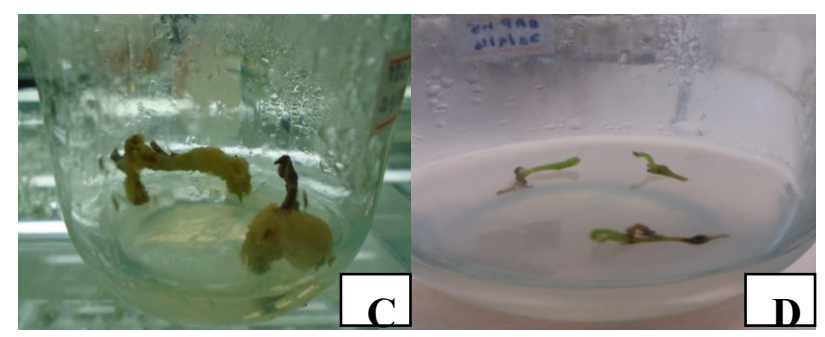

Figure 1: C-Callus growth of shoot tips in MS basal medium supplemented with TDZ after 4 weeks of culture D- Shoot induction of In vitro grown segments after two weeks of culture.

\section{REFERENCES}

Abbas, M.F. 1997 Jujube. In: Post-harvest physiology and storage of Tropical and Sub tropical Fruits. (Mitra, K.S, ed.), CAB International, Wallingford, pp 405-415.

Azam-Ali S, 2006 Ber and other jujubes Vol. 2. Crops for the Future.UK: International Centre for Underutilized Crops, pp. 1, 19 and 29.

Chen ZL, Wang XJ, Liu SP, Cao W, Ning XJ, Qi XY and Zhang XQ 2008 September. Development of somatic embryo and adventitious buds from the differentiating cultured calli of Chinese Jujube Mu-Zao. In: International Jujube Symposium 840: 273-282.

Feng JC, Yu XM, Shang XL, Li JD and Wu YX 2010 Factors influencing efficiency of shoot regeneration in Ziziphus jujuba Mill.'Huizao'. Plant Cell, Tissue and Organ Culture (PCTOC), 101(1): 111-117.

Goyal D, Bhadauria S and Kumar A 2006 A protocol for in vitro propagation of ber (Ziziphus jujuba). Indian journal of plant physiology, 11 (2): 178-181.

Gu XF and Zhang JR 2005 An efficient adventitious shoot regeneration system for Zhanhua winter jujube (Zizyphus jujuba Mill.) using leaf explants. Plant cell reports, 23(12): 775779 .

Hopkins WG, Müner NPA 2008 Introduction to plant physiology. J. Wiley and Sons U.S.A.

Johnstone R, Growing Chinese jujubes in WA. http://www.agric.wa.gov.au/objtwr imported_assets/content/hort/fn/cp/ fn_growing_chinese_jujubes_in_wa.pdf, 2012.

Ketepeaarachchi K 2014 Underutilized fruit crops for nutritional and health security, Department of Agriculture, Sri Lanka: 1-3, 66-71.

Kim YW, Moon HK and Son SC 2006 Repetitive somatic embryogenesis and plant regeneration in Zizyphus jujuba Mill. In Vitro Cellular \& Developmental Biology-Plant, 42(3): 247251.

Li CZ, Lian YZ, Hao XUE, Dong FX, Liang CG and Yun CJ 2002 In vitro Culture of Leaves and Plantlet Regeneration of Ziziphus jujuba var. Zhanhua-Dongzao [J]. Plant Physiology Communications, 6: 019.

Liu MJ and Qi YF 2003 September Embryo rescue of Chinese jujube (Ziziphus jujuba Mill.). In: XI Eucarpia Symposium on 
Fruit Breeding and Genetics 663: 479482.

Lu CY 1993 The use of thidiazuron in tissue culture. In Vitro Cellular \& Developmental Biology-Plant, 29(2): 92-96.

Ma C, Ye X, Chen, Y, Feng J, Shang X, Li J, Wu $\mathrm{Y}$ and $\mathrm{Hu} \mathrm{J} 2012$ Anatomical observations of adventitious bud regeneration from leaf explants of Ziziphus jujuba Mill.'Huizao'. Horticulture, Environment, and Biotechnology, 53(4): 316-319.

Murashige T and Skoog F 1962 A revised medium for rapid growth and bio assays with tobacco tissue cultures. Physiologia plantarum, 15(3): 473-497.

San B, Yildirim AN, Polat M and Yildirim F 2009 Mineral composition of leaves and fruits of some promising Jujube (Zizyphus jujuba Miller) genotypes. Asian Journal of Chemistry, 21(4): 2898.

SAS Institute Inc. 2000. SAS Online Doco, Version 8, Cary, NC: SAS Institute Inc.

Soliman HI and Hegazi GAE 2013 In vitro clonal propagation and molecular characterization of jujube (Ziziphus jujuba Mill.). Life Science Journal, 10(2): 573-582.

Sudhersan C, AboEl-Nil M and Hussain J 2000 In vitro propagation of Zizyphys mauritiana cultivar Umran by shoot tip and nodal multiplication. Current ScienceBangalore, 80(2): 290-292.

Wang G, Li X, Chen Q and Tian J 2010 August. Somatic Embryogenesis and Plant Regeneration from Cotyledons of Immature Embryo of Chinese Jujube (Zizyphus jujuba Mill.). In:XXVIII International Horticultural Congress on Science and Horticulture for People (IHC2010): International Symposium on Micro and Macro Technologies for Plant Propagation and Breeding in Horticulture 923: 33-38.

Ye X, Chen Y, Li J, Yu X, Feng J and Zheng X 2012 Callus induction and adventitious shoot regeneration in Zizyphus jujuba Mill.'Huizao'. African Journal of Biotechnology, 11(16): 3888. 